\title{
Buckling Modes of Cold-Formed Steel Columns
}

\author{
Thomas H.-K. Kang, Kenneth A. Biggs, and Chris Ramseyer
}

\begin{abstract}
The goals of this study are to understand different buckling modes, determine the buckling mode and maximum buckling capacity of the built-up $C$-channels, and evaluate the AISI-2001 Specification. For these goals, the following was conducted: 1) different buckling modes of cold-formed steel columns were investigated; 2) previous research on built-up columns and testing rigs for column buckling was reviewed; and 3 ) the authors' buckling test results of 42 cold-formed built-up columns were examined. The study and review help better understanding of the buckling modes and the effect of design or testing parameters on the buckling behavior. The results show inconsistencies in the calculated values by AISI-2001 as compared to the maximum capacity loads determined from the buckling tests. The orientation of the member substantially impacts the maximum load of the member.
\end{abstract}

Index Terms-Buckling capacity, buckling modes, built-up sections, cold-formed steel, column, distortional buckling.

\section{INTRODUCTION}

One of the biggest difficulties with cold-formed steel design is the prevention of member buckling. Because of the low thickness to width ratio, it is likely that the members will buckle at stresses that are lower than the yield stress when compressive, bearing, and shear bending forces are applied. Therefore, buckling is a major design consideration for all cold-formed steel, which is unlike the behavior of hot-rolled steel where steel yielding is the leading design consideration.

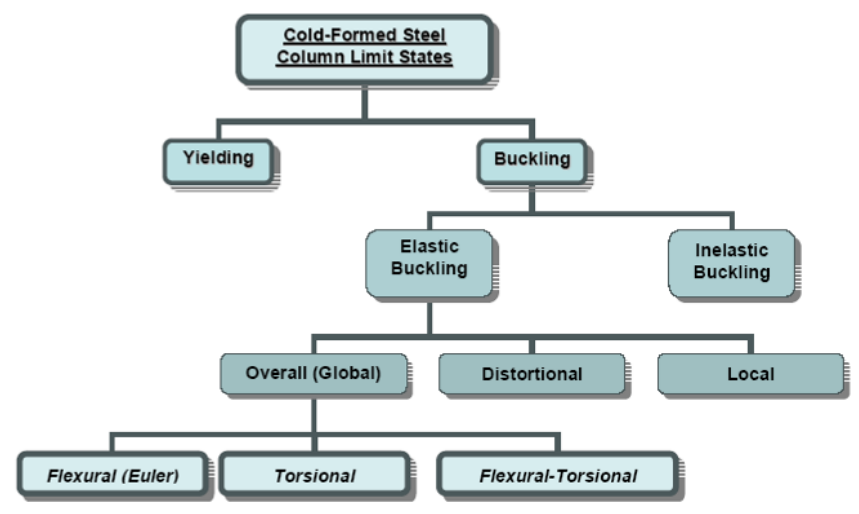

Fig. 1. Cold-formed steel column limit states.

There are two limit states for compression members: yielding and overall buckling (see Fig. 1). Yielding is mainly

Manuscript received February 10, 2013; revised May 6, 2013. This work was supported by the University of Oklahoma and by the National Research Foundation of Korea.

T. H.-K. Kang is with Seoul National University, Seoul 151-744 Korea (e-mail: tkang@ snu.ac.kr).

K. A. Biggs was with the University of Oklahoma, OK 73019 USA.

C. Ramseyer is with the University of Oklahoma, OK 73019 USA an issue for compact and short columns. The yielding of the steel causes the failure of the entire column. For longer columns, it is likely that buckling will control rather than yielding of the member. There are multiple factors that can cause a compression member to buckle. The slenderness ratio, which is the member length divided by the least radius of gyration, is the primary influence on buckling. However, buckling is impacted by other factors, which include end condition of the member, eccentricity of the load, and imperfections within the material.
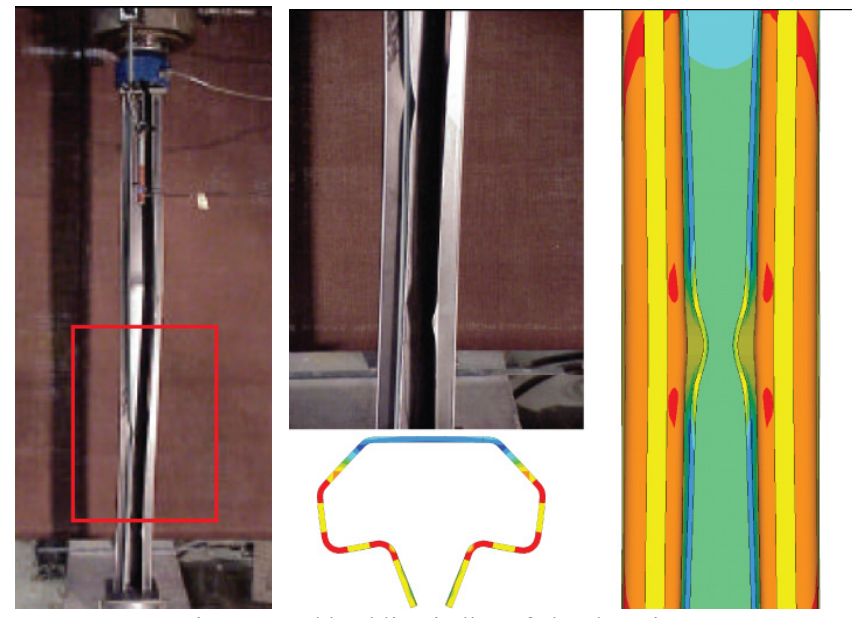

Fig. 2. Local buckling in lips of chord section.

Buckling can occur both elastically and inelastically. Inelastic buckling often occurs in stocky and intermediate columns because these columns have slenderness ratios that are in the small to moderate range. Among various buckling modes, distortional buckling is a buckling mode that has recently been investigated [1]-[4]. It is a buckling of the compression flange acting as a group of plates rather than as individual plates. The distortional buckling was less understood than the other forms of instability, and was deemed more pertinent to thinner sections of high strength steel. Distortional buckling was addressed within the code for the first time in the 2001 edition of American Iron and Steel Institute (AISI) Specification, and has not been updated until 2007. The importance of distortional buckling should not be underestimated as it is just as likely to occur as local buckling. Local buckling is often seen as a rippling effect in the web, flange, or lip along the length of the member (Figs. 2 and Fig. 3). The need for research of distortional buckling has increased as cold-formed design has shifted towards increasingly stiffened and slender sections that demand a more thorough evaluation of local and distortional buckling. As such, there is a need to perform additional tests on shorter built-up members more disposed to distortional or local buckling effects. 


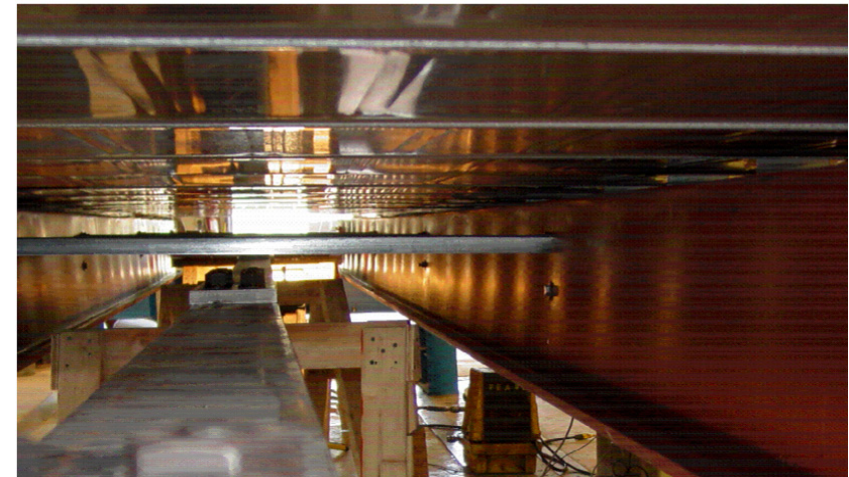

Fig. 3. Local buckling along web of Z-purlin.

\section{GOALS OF RESEARCH}

The analysis of cold-formed members comes from the 2001 edition of the American Iron and Steel Institute (AISI), North American Specification for the Design of Cold Formed Steel Structural Members. Note that when this experimental research was conducted, the 2001 edition was available, which has been updated to the 2007 edition of AISI Specification. Sections C4 and D1.2 have been updated to estimate the distortional buckling and flexural-torsional buckling failure mode (Fig. 4) and capacity of cold-formed sections.
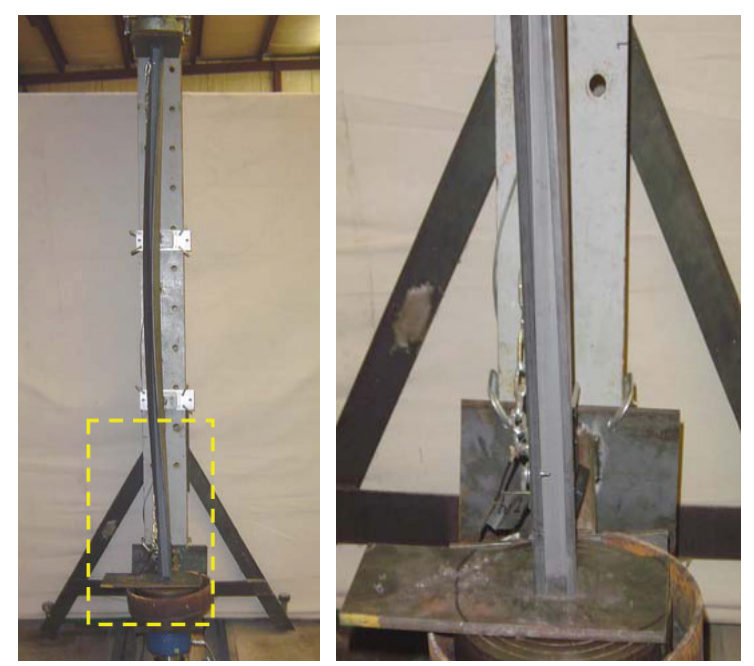

Fig. 4. Flexural-torsional buckling of C-channel column.

The goals of this study are to understand different buckling modes, determine the buckling mode and maximum buckling capacity of the cold-formed built-up C-channels, and evaluate the AISI-2001 Specification. The effects of the geometrical properties such as thickness and width of the member are attempted to be determined. For these goals, the following is conducted: 1) different buckling modes of cold-formed steel columns are investigated; 2) previous research on built-up columns and testing rigs for column buckling is reviewed; and 3) the authors' buckling test results of 42 cold-formed built-up columns are examined [5].

\section{BuILT-UP MEMBER RESEARCH}

Much of the current understanding of built-up members is based on hot-rolled built-up sections. Only a handful of experiments of cold-formed built-up sections were conducted

\section{[1], [6]-[8].}

Experimental testing, finite element analysis, and theoretical buckling stress calculations conducted by Sukumar and Parameswaran [6] were used to develop analytical models for axially and eccentrically loaded cold-formed, open built-up compression members undergoing flexural-torsional buckling. The application of formulas that were developed by Sukumar and Parameswaran [6] has proposed a curve to calculate the maximum strength of cold-formed, built-up sections in open cross-sections experiencing local and local-distortional buckling.

Stone and LaBoube [8] at the University of Missouri at Rolla studied the buckling behavior of cold-formed steel studs. The studs were formed by attaching two wide and thin $\mathrm{C}$-sections that were attached in an I-shape orientation, and connected with screws. The purpose of this research was to evaluate the 2001 AISI design equations, including the slenderness modification ratio, for built-up compression members. Their research of 32 built-up, cold-formed studs supported the conclusions that the 2001 AISI design specification is conservative for built-up members.

Brueggen and Ramseyer [7] at the University of Oklahoma compared the experimental buckling capacities to the ultimate buckling capacity calculated from the 2001 AISI Specification equations. The implications of the modified slenderness ratio and fastener provision in AISI Section C4.5 were addressed in this research. Brueggen and Ramseyer [7] noted the inconsistency of this cold-formed provision is due to the provision being substantially taken from research in hot-rolled built-up members despite the fact that the critical buckling modes found in cold-formed steel, including local and distortional buckling, rarely are a factor in hot-rolled steel sections. About 45 tests revealed that the 2001 AISI Specification is conservative for compact members but is unconservative for slender members.

A continuation of this research by Whittle and Ramseyer [1] was done to confirm the original research and examine the behavior of cold-formed, built-up members of a longer length. A total of 153 experimental tests were completed on closed orientation built-up members. The Whittle and Ramseyer [1] research found that use of the modified slenderness ratio is more conservative for longer built-up members and thicker built-up sections. These test results confirmed the findings of Brueggen and Ramseyer [7].

\section{Testing Rigs for COLUMn BuCKLing}

For the testing of the columns in axial compression, alternate tests and measurements on the steel material need to be done to ensure the consistency and tolerances between all of the specimens. The material information is important in the late stages of research when computer modeling and comparing test results to prediction equations. Ellobody and Young [9] suggest taking the material for the coupons from the "center of the flange plate in the longitudinal direction of the finished specimen."

It is important in the fabrication process to limit errors for the specimen testing. Young and Rasmussen [10] note that their research involved milling the end of each specimen flat 
with an electronic milling machine, which ensures total contact between the specimen and end bearing.

Assembling the test rig includes determining the loading equipment, the restraining structure, and the measuring apparatus. The Structural Stability Research Council (SSRC [11]) provides specific guidelines for column stability testing, "Guide to Stability Design Criteria for Metal Structures." Within these guidelines are descriptions of typical test rigs and associated elements.

The end connections of the column test rig are essential in the test setup. The boundary conditions of the column can vary from a simple pinned end condition to a fixed end condition. The effective length factor is dependent on the end condition used, and will affect the predicted capacity of the section. Pinned end restraints, which give an effective length factor $(k)$ of 1 , are recommended because these restraints cause the critical cross-section of the column to be located at the middle of the column so that the critical section is less influenced by the end effects [11]. While in all other cases the effective length is simply the length of the column.

\section{BuCKLING TESTS}

\section{A. Description}

The columns were tested in axial compression with pinned end connections and in two different orientations, one with the C-channels facing each other to produce a closed shape (rectangular), and the other orientation had the members facing away (referred to as an I-shaped hereafter) [5]. Fig. 5 shows the rectangular and I-shaped orientations, respectively. Both orientations were tested to determine if orientation affects the failure pattern and if one orientation leads to a higher failure load than the other. The closed R-section provides exceptional torsional resistance, which could lead to an increased buckling capacity.

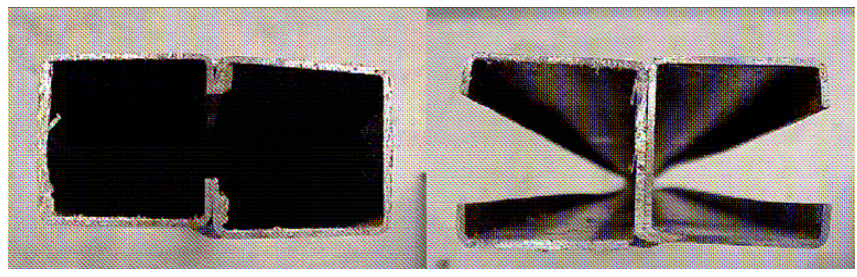

Fig. 5. Rectangular and I-shaped cold-formed built-up sections.

One test for each member type was used to determine each of the buckling values. All specimens were unique and explored a different specimen type.

Not all of the built-up columns that were tested were in compliance with the fastener spacing requirements of the AISI-2001 Specification. The reason for testing some columns that did not meet the Specification requirements was to evaluate the AISI-2001 Specification.

\section{B. Specimens}

All members were created from two, lipped C-channels which were connected by $102 \mathrm{~mm}$ long welds at the top and bottom, in accordance with AISI-2001 Section D1.2. There were also intermediate weld locations throughout the member which had a weld length of $25 \mathrm{~mm}$. The different intermediate weld patterns are shown in Fig. 6. All welds were approximately $4.8 \mathrm{~mm}$ thick.

\begin{tabular}{|c|c|c|}
\hline \multicolumn{2}{|r|}{ Welded Atzchment Oriertation } & Description \\
\hline$\sqsubset$ & $\square$ & single \\
\hline ᄃ & $\underset{\sim}{\longrightarrow}$ & double \\
\hline$[\bar{c}$ & $x$ & swit \\
\hline$[\beth$ & $\ddot{x}$ & Din1 \\
\hline$[\overline{\ulcorner} 3$ & $\underset{x}{x}$ & $\sin 2$ \\
\hline[]$_{3}$ & 姲 & DWw2 \\
\hline[]$_{6}$ & 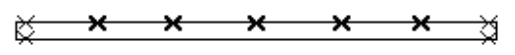 & sins \\
\hline \multirow[t]{2}{*}{$\beth_{6}$} & $\underset{x}{x} \underset{x}{x} \underset{x}{x} \underset{x}{x} \underset{x}{x}$ & DWw5 \\
\hline & $X=1 "$ Interme diate Wi elds & \\
\hline
\end{tabular}

Fig. 6. Intermediate attachment descriptions.

The thickness of the $\mathrm{C}$-channels was a variable during the experimental testing. The thicknesses chosen were based off common built-up members used in cold-formed trusses. There were a total of three nominal thicknesses used in the testing which were 1.6, 2 and $2.5 \mathrm{~mm}$. All of the members tested had a web length of $92 \mathrm{~mm}$ and were square in shape. This was the only web length investigated during the testing, because previous testing [1] focused on smaller web lengths of 41 and $67 \mathrm{~mm}$.

Besides the variable thickness, the change in the number of intermediate welds and column length made up the other varying factors in the built-up specimen. In addition to the locations of the intermediate welds described in Fig. 6, the welds were also tested on just a single side of the member and both sides of the member.

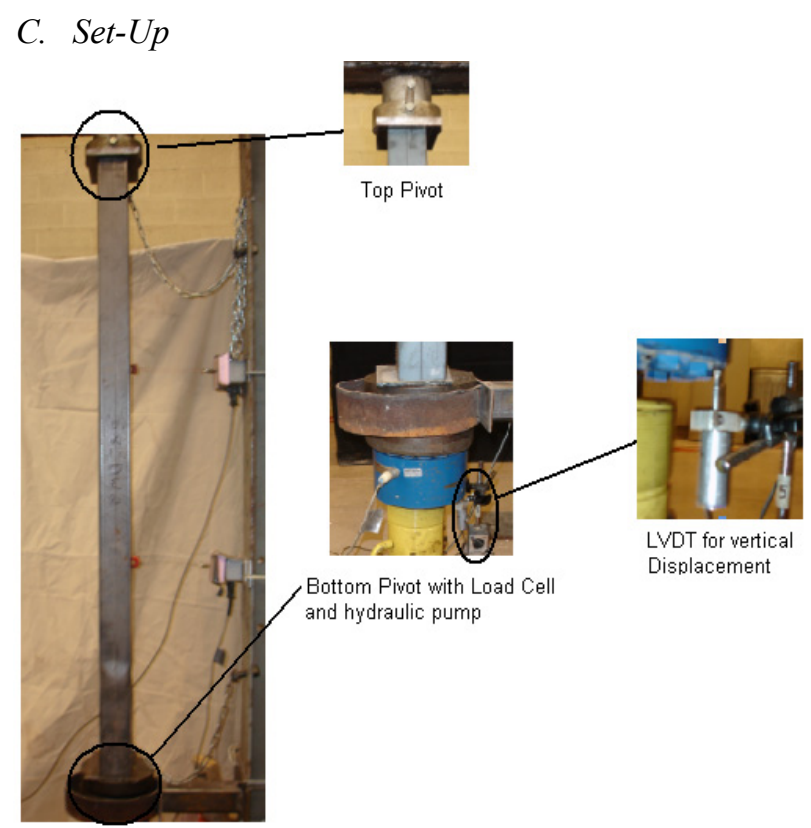

Fig. 7. Test setup for $1.8 \mathrm{~m}$ long column (that failed in distortional buckling)

The loads were applied using a hand pump that is attached to a hydraulic pump, allowing the operator to easily control the rate of loading. On each end of the test is a greased swivel 
pivot which allows for a pinned connection and an effective length coefficient value of 1 . The column set between the 2 pivots in an upright position (Fig. 7). The chains around the column are safety restraints used for safety to prevent the specimen from propelling out of the test setup after failure had occurred.

\section{Testing}

The fabrication process involved multiple steps. The first step was welding the two C-channels together. Clamps were placed throughout the specimen to ensure that the heat of the welds would not cause the member to spread apart before the C-channels could be fully welded together. The welding included the $102 \mathrm{~mm}$ long welds on each end of the specimen and $25 \mathrm{~mm}$ long welds at the intermediate attachments. The end welds were started $25 \mathrm{~mm}$ from the edge of the C-channels: this allowed the members to be cut on a band saw as one piece after the welding process to ensure the edges were flat and proper bearing on the pivots occurred. After welding, the members were cut to the proper lengths of $1.8 \mathrm{~m}$.

Before each column was placed in the test rig a plum bob was used to ensure that all pieces of the test setup were in line so the force on the column would be purely axial. The specimen was placed in the test rig with just enough pressure to hold the specimen still while at the same time allowing any final adjustments to be made to the specimen to line it up with the rest of the setup. A safety chain was connected from the specimen to a frame column behind the test setup, which can be seen at the top of Fig. 7. Finally, the wire potentiometers for lateral displacement were magnetically connected to the specimen, and the LVDT for vertical displacement was connected to the bottom of the load cell. From a safe distance and location, the operator began to add the load using the hand pump for the $1.8 \mathrm{~m}$ test. The final buckling of the specimen was usually apparent by either the load vs. axial shorting graph or a sudden failure where the specimen would attempt to come out of the test rig after buckling.

\section{BuCKLING TESt RESUlts}

\section{A. Rectangular Columns}

The maximum buckling capacity of the column $\left(P_{\text {test }}\right)$ was the largest axial load applied to the column when failure occurred. The nominal loads of the columns $\left(P_{n}\right)$ were calculated in accordance with AISI-2001 Specification.

The test results of the $92 \mathrm{~mm}$ wide built-up rectangular columns were compared to the previous experimental results of the same columns but with smaller widths of 41 and 67 $\mathrm{mm}$ [1]. The results were compared to see if the same patterns appeared for the larger columns as did with the smaller ones. The main pattern of interest was an increase in the $\left(P_{\text {test }} / P_{n}\right)$ ratio for thicker material, which means the AISI-2001 Specification becomes more conservative for thicker columns. Fig. 8 shows the $\left(P_{\text {test }} / P_{n}\right)$ ratio from the previous research for both 41 and $67 \mathrm{~mm}$ wide columns having a length of $1.4 \mathrm{~m}$ or $1.8 \mathrm{~m}$. Fig. 9 shows the pattern that formed during the current research of $92 \mathrm{~mm}$ wide columns with a $1.8 \mathrm{~m}$ length.

From visual comparison of these graphs, it can be seen that for rectangular $1.8 \mathrm{~m}$ built-up columns the same pattern occurs, where the ratio becomes more conservative with a greater thickness. However, another pattern is generated from the comparison of all three graphs. It can be seen by comparing Fig. 8 and Fig. 9 that the $\left(P_{\text {test }} / P_{n}\right)$ ratio is getting closer to 1.0 and less conservative the larger the column width becomes. Looking at Fig. 9 the ratio becomes about 1.0 for the $1.6 \mathrm{~mm}$ section which results in a non-conservative calculated nominal capacity. Overall, the axial capacity was conservative for all $1.8 \mathrm{~m}$ columns. The $1.6 \mathrm{~mm}$ thick column with third-point single sided welds was the least conservative out of all $1.8 \mathrm{~m}$ long specimens, at a value of $9 \%$ conservative. The most conservative column had a value of $118 \%$ conservative and came from the $2.5 \mathrm{~mm}$ thick column with double-sided third-point intermediate welds.

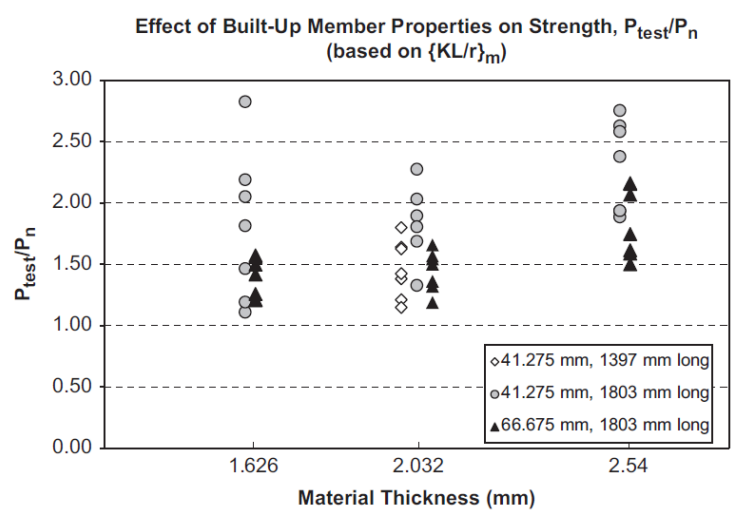

Fig. 8. $\left(P_{\text {test }} / P_{n}\right)$ ratio for previous columns (Whittle and Ramseyer, [1]).

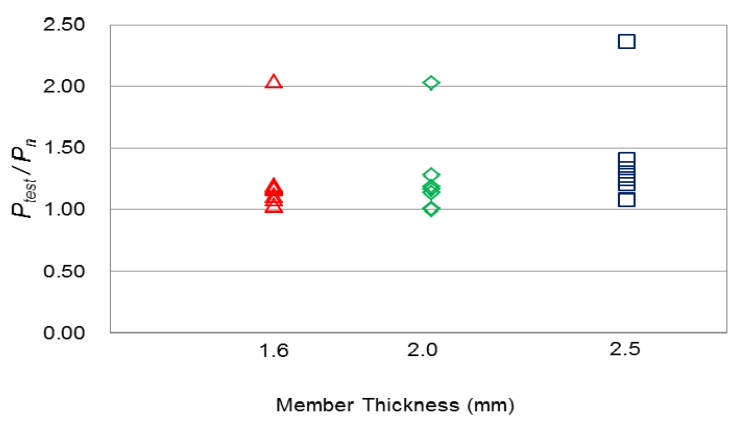

Fig. 9. $\left(P_{\text {test }} / P_{n}\right)$ ratio for $92 \mathrm{~mm}$ wide, $1.8 \mathrm{~m}$ long columns.

\section{B. I-Shaped Columns}

The tests of the I-shaped orientation were done to see if there is a significant change in the maximum axial buckling capacity of the column with a change in orientation. The same tests that were performed on the rectangular sections were chosen for the I-shaped column tests. The final data are compared to the results of the rectangular columns along with seeing if all the same trends are present in the I-shaped columns that were discussed in the preceding section. Fig. 10 shows the $\left(P_{\text {test }} / P_{n}\right)$ ratio for the $1.8 \mathrm{~m}$ long I-shaped columns.

For the I-shaped orientation the overall trend of an increase in the $\left(P_{\text {test }} / P_{n}\right)$ ratio with an increase in member thickness remains true. Out of the columns that meet the AISI-2001 specification, all tested $1.8 \mathrm{~m}$ columns had a conservative value.

When the buckling load of the $1.8 \mathrm{~m}$ long rectangular columns is compared to that of the I-shaped columns, it can be seen that the I-shaped columns have a lower buckling capacity than that of the rectangular columns. The $1.6 \mathrm{~mm}$ 
thick I-shaped columns are an average of $11 \%$ lower than the $1.6 \mathrm{~mm}$ thick rectangular columns. The $2 \mathrm{~mm}$ thick I-shaped columns are an average of $20 \%$ lower, and the $2.5 \mathrm{~mm}$ thick I-shaped columns are also an average of $20 \%$ lower.

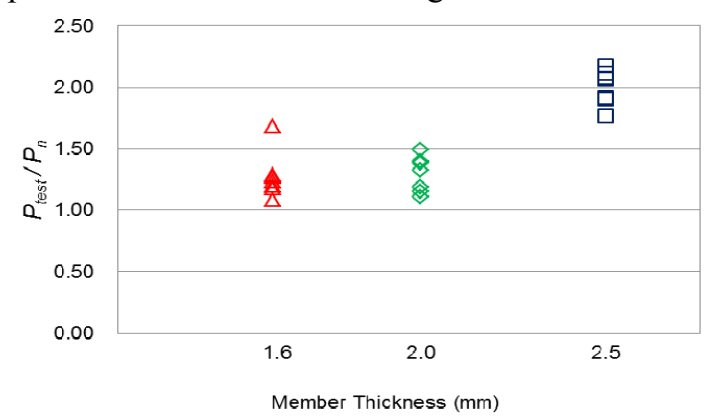

Fig. 10. $\left(P_{\text {tess }} / P_{n}\right)$ ratio for $1.8 \mathrm{~m}$ long I-shaped orientation.

There are significant differences between rectangular and I-shaped columns for the $1.8 \mathrm{~m}$ columns. These lower capacities for I-shaped columns are also resulting in a less conservative nominal capacity calculation. It can be seen that many of the I-shaped columns are unconservative while all of the rectangular columns have a conservative value.

\section{Buckling Modes}

The rectangular $1.8 \mathrm{~m}$ specimens normally failed in a form of global buckling. However, this was not always the case and the intermediate weld attachments did have a factor in the final failure pattern of the column. For the single-sided welds of the 1.6 and $2 \mathrm{~mm}$ thick members the failure pattern was flexure buckling with a separation of the flanges on the opposite side as the intermediate welds. For $2.5 \mathrm{~mm}$ thick members, the five intermediate single-sided welds along with all double-sided weld patterns failed by either a crushing of the end or an individual buckling of the flanges. No flexural buckling occurred on the column; instead it was these distortional buckling modes that failed the column. Figs. 7 and Fig. 11 show distortional buckling failures.

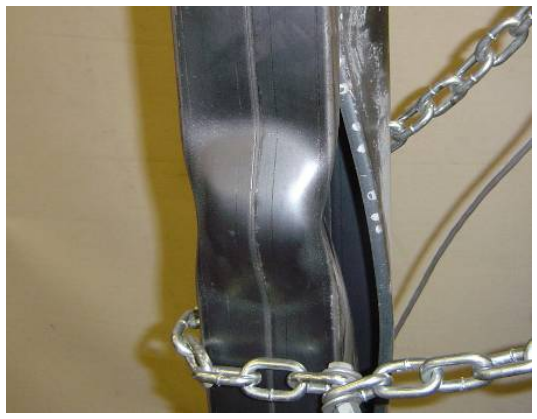

Fig. 11. Distortional buckling.

The I-shaped $1.8 \mathrm{~m}$ long columns were much more susceptible to distortional buckling of the flange and web than the rectangular columns. The majority of the I-shaped columns failed in a form of distortional buckling. These failures consist of distortional buckling of the flange and web, along with some failing by crushing at the end.

\section{CONCLUSION}

The study and review helped better understanding of the buckling modes and the effect of design or testing parameters on the buckling behavior. The results show inconsistencies in the calculated values by AISI-2001 as compared to the maximum capacity loads determined from the buckling tests. The orientation of the column substantially impacts the maximum load of the column (as much as 20\%).

\section{REFERENCES}

[1] J. Whittle and C. Ramseyer, "Buckling capacities of axially loaded, cold-formed, built-up C-channels," Thin-Walled Structures, vol. 47, no. 2, pp. 190-201, Feb. 2009.

[2] T. H.-K. Kang, K. Piyawat, and C. Ramseyer, "Design buckling strength curve for built-up cold-formed sections," in Proc. $6^{\text {th }}$ Int. Symp. on Steel Structures, Seoul, Korea, Nov. 2011.

[3] K. Piyawat, C. Ramseyer, and T. H.-K. Kang, "Nonlinear buckling of built-up cold-formed sections," Int. J. Theoretical and Applied Multiscale Mechanics, vol. 2, no. 2, pp. 146-164, Nov. 2011.

[4] K. Piyawat, C. Ramseyer, and T. H.-K. Kang (Dec. 2012). Development of an axial load capacity equation for doubly-symmetric built-up cold-formed sections. ASCE J. of Structural Engr. [Online]. Available:http://ascelibrary.org/doi/abs/10.1061/\%28ASCE\%29ST.19 43-541X.0000780.

[5] K. A. Biggs, "Axial load capacity of cold-formed built-up members," MS thesis, The University of Oklahoma, Norman, OK, 2008.

[6] S. Sukumar and I. L. S. Parameswaran, "Local-, distortional-, and Euler buckling of thin walled built-up open cross-sections under compression," J. Structural Engr. India (SERC), vol. 32, no. 6, pp. 447-454, Feb.-Mar. 2006.

[7] B. Brueggen and C. Ramseyer, "Cold-formed steel joist member buckling capacity testing," Technical Report, Donald G. Fears Structural Engineering Laboratory, The University of Oklahoma, Norman, OK, 2003.

[8] T. A. Stone and R. A. LaBoube, "Behavior of cold-formed steel built-up I-sections," Thin-Walled Structures, vol. 43, no. 12, pp. 1805-1817, Dec. 2005.

[9] E. Ellobody and B. Young, "Behavior of cold-formed steel plain angle columns," ASCE J. Structural Engr., vol. 131, no. 3, 457-466, Mar. 2005.

[10] B. Young and K. J. R. Rasmussen, "Inelastic bifurcation of cold-formed singly symmetric columns," Thin-Walled Structures, vol. 36, no. 3, pp. 213-230, Mar. 2000.

[11] T. V. Galambos, Guide to Stability Design Criteria for Metal Structures, $5^{\text {th }}$ ed. Structural Stability Research Council, Wiley, 944, 1998.

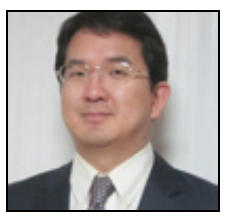

Thomas Kang is an assistant professor of architectural engineering at Seoul National University, Seoul, Korea, and a licensed Professional Engineer (P.E.) in CA, U.S.A. Before that, he was an assistant professor of civil engineering at the University of Oklahoma. Prof. Kang's research interests include a number of subjects relating to the design, repair and materials of structural concrete and steel. He received American Concrete Institute (ACI) Wason Medal for Most Meritorious Paper in 2009 and the Post-Tensioning Institute (PTI) Fellow award in 2012.

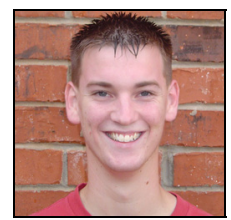

Kenny Biggs was a graduate student of civil engineering at the University of Oklahoma, Norman, OK, U.S.A. He received his B.S. and M.S. from the University of Oklahoma. Mr. Biggs' research interests include the design and behavior of cold-formed steel columns.

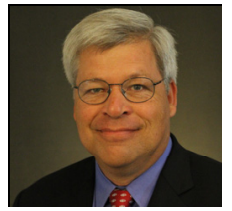

Chris Ramseyer is an associate professor of civil engineering at the University of Oklahoma (OU), Norman, OK, U.S.A, and a licensed Professional Engineer (P.E.) in OK and CA, U.S.A. Prof. Ramseyer's research interests include metal building and bridge issues, structural stability, and application of analytical and experimental testing techniques to structural systems. He received OU Alumni Teaching award in 2007 and the George Tauxe faculty teaching award in 2004 and 2011. 